\title{
Globalização e Educação: a integração entre a rede federal de Educação Profissional, Científica e Tecnológica e os processos migratórios no Brasil no século XXI
}

\author{
Globalization and Education: the integration between the federal network \\ vocational, scientific and technological education and migratory \\ processes in Brazil in the 21st century
}

Recebido: 29/05/2020 | Revisado: 01/06/2020 | Aceito: 06/10/2020 | Publicado: $17 / 02 / 2021$

Rayna Sargem da Silva

ORCID: https://orcid.org/0000-0003-38852754

Instituto Federal de Educação, Ciência e

Tecnologia Fluminense

E-mail: rsargem@gmail.com

Jefferson Manhães de Azevedo

ORCID: https://orcid.org/0000-0001-50102230

Instituto Federal de Educação, Ciência e

Tecnologia Fluminense

E-mail: jazevedo@iff.edu.br

\section{Como citar:}

SILVA, R. S; AZEVEDO, J. M.;

Globalização e Educação: a integração entre a rede federal de Educação

Profissional, Científica e Tecnológica e os processos migratórios no Brasil no século XXI. Revista Brasileira da Educação Profissional e Tecnológica, [S.I.], v. 1, n. 20, p. e10288, fev. 2021. ISSN 2447-1801. Disponível em:

$<$ http://www2.ifrn.edu.br/ojs/index.php/RBE PT $>$.

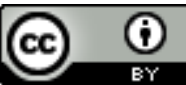

This work is licensed under a Creative Commons Attribution 4.0 Unported License.

\begin{abstract}
Resumo
Este artigo visa analisar os caminhos pelos quais a Rede Federal de Educação Profissional, Científica e Tecnológica tem se organizado frente as necessidades geradas pelos processos migratórios no país, no século $\mathrm{XXI}$. Segundo as garantias asseguradas aos migrantes na Lei da Migração, Lei № 13.445, de 24 de maio de 2017, questiona-se se as condições de ensino e de trabalho aos migrantes no Brasil acompanharam tal crescimento. Nesse cenário, aponta-se a Rede Federal de Educação Profissional, Científica e Tecnológica como uma possível estratégia de política pública para a inserção qualificada dos migrantes e refugiados no mundo do trabalho.
\end{abstract}

Palavras-chave: Educação Profissional e Tecnológica; Globalização da educação; Migração.

\begin{abstract}
This article aims to analyze the ways in which the Federal Network of Vocational, Scientific and Technological Education has been organizing facing the needs generated by the migratory processes in the country in the 21 st century. According to the guarantees provided to migrants in the Migration Law, Law No. 13,445, of May 24, 2017 , it is questioned whether the conditions of education and work for migrants in Brazil have accompanied such growth. In this scenario, the Federal Network of Vocational, Scientific and Technological Education is pointed out as a possible public policy strategy for the qualified insertion of migrants and refugees in the world of work.
\end{abstract}

Keywords: Vocational and Technological Education; Globalization of Education; Migration. 


\section{INTRODUÇÃO}

O mundo do trabalho, no século XXI, assume características de heterogeneidade, complexidade e fragmentação se comparado à organização do trabalho em meados do século anterior. Antunes e Alves (2004) apontam uma das principais tendências para que esta nova configuração no mundo do trabalho ocorra: o capitalismo mundializado. Nesse contexto de transnacionalização do capital, a organização do mundo do trabalho também se configura, cada vez mais, em aspectos globais. Nas palavras de Antunes e Alves (2004),

Com a reconfiguração, tanto do espaço quanto do tempo de produção, novas regiões industriais emergem e muitas desaparecem, além de inserirem-se, cada vez mais, no mercado mundial, como a indústria automotiva, na qual os carros mundiais praticamente substituem 0 carro nacional (ALVES, 2004, p. 341).

A transnacionalização do capital ocorre, então, a partir da desestabilização dos sistemas produtivos de cada nação. Desestabilização, essa, acarretadas por organizações multinacionais. Esse processo gerou mudanças na economia global e, por consequência, resultou num cenário de acumulação mundial. Essas mudanças lideradas "pelas instituições corporativas do capital, a expansão da reestruturação das forças produtivas, bem como a ampliação do fenômeno da financeirização e da mundialização do capital ${ }^{1 "}$ (TORRES, 2012, p. 47) formataram uma nova fase do capitalismo (TORRES, 2012).

A transnacionalização do capital também resulta na ampliação das fronteiras da organização do trabalho, com o surgimento de uma classe de trabalhadores mundializados, desenvolvida na mescla das dimensões locais, regionais, nacionais e internacionais (ANTUNES; ALVES, 2004).

Faz-se necessário, então, trazer à tona outra vertente que, embora não seja recente, se fortaleceu em meio aos movimentos de globalização: a migração ${ }^{2}$. Segundo dados do Relatório Mundial da Migração (OIM, 2019), elaborado pela Organização Mundial da Imigração (OIM), em 2019, o número de migrantes no mundo chegou à marca de 272 milhões de pessoas.

Em 2018, a Organização das Nações Unidas (ONU) elaborou o Pacto Mundial para a Migração (ONU, 2018), documento do qual participam 164 países. Esse pacto tem os seus objetivos delineados pela busca de uma equalização internacional de cooperação aos estimados 68 milhões de migrantes ao ano no mundo. Tal negociação seria responsável por fazer com que os Estados se responsabilizassem em garantir

\footnotetext{
1 "O processo denominado mundialização do capital pode ser definido como uma reestruturação do capitalismo em novas bases econômicas, como meio de recuperar as taxas de acumulação das décadas anteriores" (FERRER, 2001, p. 19).

${ }^{2} \mathrm{O}$ fenômeno da migração acontece quando pessoas se deslocam de uma nação a outra, seja por razões individuais, como casamento com estrangeiros, aposentadoria, turismo, ou por questões de conflitos ou dificuldades coletivos a um povo (FRANCO FILHO, 2015).
} 
que os Direitos Humanos fossem cumpridos aos migrantes, assegurando-lhes a segurança, reintegrando-os à vida cidadã e combatendo o tráfico de pessoas e de trabalho escravo (ONU, 2018).

Contudo, questiona-se se o alto número de cidadãos migrantes consegue exercer, plenamente, sua cidadania no país onde se encontram, principalmente no que se diz respeito ao acesso do migrante à educação e ao trabalho. Será que as esferas educacionais têm se organizado de forma capaz de atender às demandas dos migrantes? Será que os governos têm criado políticas públicas capazes de alcançar esse público?

Atentando-se nesse artigo, especificamente, sobre a realidade brasileira, questiona-se de que maneira os migrantes e refugiados conseguem ter acesso à educação e a auferir postos de trabalho, na atual conjuntura do país. De maneira mais precisa, analisa-se a Rede Federal de Educação Profissional, Científica e Tecnológica como um espaço no qual esses estrangeiros conseguem acesso à educação profissional e tecnológica a fim de se inserirem no mundo do trabalho.

Para tanto, esse artigo está dividido em três partes. Na primeira, serão avaliadas as relações entre os processos de globalização e as novas demandas, geradas por esses processos, nos sistemas educacionais, inclusive no contexto da Educação Profissional e Tecnológica. Na segunda, serão analisados dados da migração, no Brasil, na última década. E, por fim, discutir-se-á como a Rede Federal de Educação Profissional, Científica e Tecnológica têm criado ações em meio às demandas da internacionalização e da migração.

\section{A RELAÇÃO ENTRE A GLOBALIZAÇÃO E A EDUCAÇÃO}

A globalização não representa um processo novo, visto que já começava a se constituir desde meados do Século XIX (CAMPOS; CANAVEZES, 2007). Porém, os processos globais são componentes cada vez mais presentes da sociedade contemporânea. A aceleração do fenômeno da globalização se deu a partir de fatores como os avanços tecnológicos, o capitalismo neoliberal, as trocas supranacionais, cada vez mais rápidas, e, principalmente, com a integração entre os países em largas escalas. Para Sander (2008, p.158), a globalização "representa, hoje, a crescente gravitação dos processos econômicos, políticos e culturais, de caráter mundial, sobre os processos de caráter regional, nacional e local" .

Compreendida como um processo complexo, abrangente e de escala mundial, a globalização é um fenômeno que tem como característica a chamada desterritorialização, movimento no qual as relações são desvinculadas dos seus próprios espaços locais. Um aporte para este movimento seria o desenvolvimento tecnológico que aprimora a comunicação e facilita a circulação de pessoas, bens e serviços (CAMPOS; CANAVEZES, 2007).

Se a globalização impacta as sociedades de maneira global, questiona-se se a relação entre tal fenômeno e os indivíduos é sinônimo de benefícios para todos. Nesse momento, torna-se importante citar o documentário Encontro com Milton Santos: O mundo global visto do lado de cá (2006). No documentário, Milton Santos discute a globalização sob a perspectiva dos dominantes e dos dominados. 
A globalização mostra-se altamente benéfica tanto para os Estados desenvolvidos, principalmente no contraste Norte versus Sul, quanto para as grandes corporações. Ela amplia os mercados e estimula o consumo, aumentando o domínio dos mesmos sobre o planeta. Porém, a globalização gera a fábula de sociedade independente do Estado, o que resulta na precarização do atendimento às sociedades presentes nos países subdesenvolvidos. Nesse cenário, a pobreza e o desemprego aumentam, junto com a generalização da fome, do desabrigo e da exploração de mão de obra.

No contexto altamente globalizado, há de se esperar que a educação também seja impactada. Nesse sentido, Thiesen (2018), propõe que os processos de mundialização/globalização do capital, junto aos rearranjos estruturais dos estados nacionais, frente aos movimentos migratórios, as demandas por tecnologia e a força das questões culturais, nas relações sociais, resultariam na necessidade de novos arranjos nas políticas, em diversos níveis da educação. Portanto, estados nacionais e organismos transnacionais ${ }^{3}$ estariam estimulados a impulsionar movimentos de internacionalização, desde a educação básica até a educação superior.

A importância do conhecimento na sociedade globalizada já era explicitada em 1993, pela Organização das Nações Unidas para a Educação, a Ciência e a Cultura (UNESCO) no documento Learning: The treasure within (UNESCO, 1993). O referido documento aborda a necessidade de uma educação de qualidade para a formação cidadã, no cenário global, sendo o saber um fator chave ao desenvolvimento individual, social, local e internacional.

Mais recentemente, a UNESCO tem trabalhado com o conceito de Educação para a Cidadania Global (ECG). Segundo a organização, a cidadania global, embora não seja recente, se tornou ainda mais significativa a partir da "Iniciativa Global Educação em Primeiro Lugar" (GEFI), em 2012, que identificou o "fomento à cidadania global" como uma de suas três áreas prioritárias de trabalho, junto ao acesso e à qualidade da educação" (UNESCO, 2015, p.2). Nesse contexto, a ECG busca oferecer uma educação aos alunos, de modo que os formem cidadãos globais, por meio da equiparação de valores, conhecimentos e habilidades, alicerçadas no respeito aos direitos humanos, na justiça social, na diversidade, na igualdade de gênero e na sustentabilidade ambiental (UNESCO, 2015).

Assim, trazendo a educação globalizada para a temática deste artigo, é necessário citar a atuação do Centro Internacional para a Educação Profissional e Tecnológica, UNEVOC, instituto pertencente à UNESCO, que atua na promoção da Educação Profissional e Tecnológica, nas esferas globais, a partir de uma rede mundial de instituições a ela ligadas da qual o Conselho Nacional das Instituições da Rede Federal de Educação Profissional, Científica e Tecnológica (CONIF) faz parte, desde $2016^{4}$.

Ao compreender a Educação Profissional e Tecnológica como um campo complexo, a UNESCO/UNEVOC propõe que sua rede, composta por mais de 250

\footnotetext{
${ }^{3}$ São, estes, organismos não-estatais estruturados em diferentes territórios, por meio da chamada desfronteirização organizacional. Essas organizações exercem o seu poder a partir de relações geradas por alianças e parcerias mundiais (SANTOS, 2012).

4

Informações

disponíveis

em:

https://unevoc.unesco.org/home/Explore+the+UNEVOC+Network/centre=3063. Acesso em: 21 de maio de 2020.
} 
centros, esteja alicerçada no desenvolvimento de habilidades e competências relacionadas ao trabalho, principalmente pelo conceito de Educação para 0 Desenvolvimento Sustentável (EDS). Portanto, aufere-se que os cursos de formação profissional e tecnológica possam proporcionar aos indivíduos as habilidades necessárias para seu ingresso e atuação no mundo do trabalho, tendo em vista o desenvolvimento econômico, inclusivo e sustentável (UNESCO, 2017).

Faz-se necessário, neste momento, que se problematize o que determinaria as habilidades e competências necessárias aos indivíduos. Será que todos as pessoas teriam acesso ao mesmo modelo de ensino? Os conceitos de cidadania global seria para todos? Seria interessante às esferas dominantes que todos pudessem desenvolver plenamente suas habilidades a fim de auferir altos postos no mundo do trabalho? Afinal, a educação globalizada aconteceria para atender aos interesses de quem?

No regime de acumulação flexível, a educação constituiria o meio capaz de levar os indivíduos a desenvolverem suas competências ao longo da vida. Contudo, segundo Kuenzer e Grabowski (2016), a expansão da educação se deu de maneira precarizada, resultando num cenário de dualidade invertida. Ou seja, para os jovens mais pobres, a expansão da educação geral não teria ampliado as oportunidades de inserção no mundo do trabalho.

Se para as classes dominantes a educação os capacitaria a desenvolver plenamente suas habilidades intelectuais, para as classes mais baixas a educação flexibilizada deveria, apenas, capacitar os indivíduos a atuarem em cargos de baixa complexidade intelectual, adaptando-os ao movimento de um mercado que inclui/exclui, segundo as necessidades do regime de acumulação (KUENZER; GRABOWSKI, 2016).

Então, aponta-se para a necessidade de uma educação integral, que englobe as habilidades técnicas e intelectuais, a ser ofertada de maneira igualitária. Porém, para Moura, Lima Filho e Silva (2015), na atual conjuntura, onde o capital é regido pela burguesia dominante, ainda não seria possível a materialização da politecnia ${ }^{5}$ ou da escola unitária ${ }^{6}$ em seus sentidos plenos para todos. Contudo, já seria possível, e necessário, que se plantassem as sementes da formação humana integral, politécnica, unitária, aproveitando-se das contradições do sistema capitalista.

Nesse sentido, documento Recommendation concerning technical and vocational education and training (TVET) (UNESCO, 2015) propõe que a educação profissional deve ser ofertada a todos os jovens e adultos, de forma igualitária. Entretanto, questiona-se, no presente artigo, de que maneira os migrantes e refugiados estão inseridos nessa formatação global da Educação Profissional e Tecnológica (EPT). Esse assunto já é tema de discussão da UNESCO/UNEVOC ao considerar que, embora a imigração ainda seja entendida como um fator, na maioria das vezes desafiador e complexo no contexto global, a EPT poderia trabalhar de

\footnotetext{
${ }^{5}$ Segundo Moura, Lima Filho e Silva. (2015), Marx associa a educação politécnica à ideia de indivíduo integralmente desenvolvido, sendo ela parte da formação integral, junto a combinação de trabalho produtivo pago, educação intelectual e exercício físico.

${ }^{6} \mathrm{~A}$ escola unitária partiria, segundo o que fora proposto por Gramsci, da integração entre trabalho, ciência e cultura. Essa escola seria alternativa à escola tradicional, uma escola "desinteressada", essencialmente humanista (MOURA; LIMA FILHO; SILVA, 2015).
} 
maneira a mitigar os efeitos das crises migratórias, oferecendo um campo de desenvolvimento social e profissional aos imigrantes (UNESCO, 2019).

Analisando a situação dos migrantes, nos países de acolhimento, a UNESCO/UNEVOC percebeu algumas características comuns a esses estrangeiros. Primeiramente, foi observado que os processos migratórios poderiam implicar na saúde mental dos migrantes. Portando, seria necessário um maior acompanhamento, capaz de abrandar os traumas por eles sofridos e de auxiliá-los na construção e no reconhecimento de sua identidade no novo país (UNESCO, 2019). Além disso, também percebeu-se a dificuldade de integração dos grupos migrantes nas esferas socioeconômicas da sua nova realidade local. Essa dificuldade foi resultante dos problemas relacionados ao acesso dos migrantes aos sistemas de educação e ao seu ingresso no mercado de trabalho do novo país (UNESCO, 2019).

Após analisar os processos migratórios, que aconteceram no mundo entre 2000 e 2017, a UNESCO/UNEVOC concluiu que a relação entre a Educação Profissional e Tecnológica e os migrantes é ampla. Dentre os diversos campos de atuação, as instituições da EPT poderiam trabalhar nas seguintes esferas: no reconhecimento das habilidades e qualificações anteriores dos migrantes, na oferta de orientação linguística e profissional a esses estrangeiros e na criação de caminhos para a sua entrada nos mercados de trabalho (UNESCO, 2019).

A partir do exposto, para que se dê seguimento na delimitação territorial, proposta na temática deste artigo, percebe-se a necessidade de que se discutam os processos migratórios no Brasil nas últimas décadas. Portanto, no tópico seguinte, serão analisados os recentes processos migratórios no país, assim como os instrumentos legais, fornecidos pelo Estado brasileiro, para a integração dos migrantes e refugiados no território nacional.

\section{PROCESSOS MIGRATÓRIOS NO CONTEXTO GLOBALIZADO: UMA ANÁLISE DAS RECENTES MIGRAÇÕES NO BRASIL}

Uma das características da globalização é uma nova formatação no contexto de mobilidade humana no mundo. O deslocamento humano é um fator que existe há séculos, seja por motivações de guerras, clima, conflitos éticos ou políticos. Contudo, deve-se conferir que a globalização intensificou esses movimentos a partir da incorporação de avançadas tecnologias de comunicação, mobilidade e transporte, com o aumento das comercializações internacionais, com a integração do setor turístico e com a flexibilização do trabalho (TOSTA; KUNZ, 2014).

Com o intuito de evidenciar a definição terminológica do conceito de refugiado, será utilizado, neste artigo, a definição proposta pelo Alto Comissariado da ONU para Refugiados (ACNUR). Segundo o ACNUR:

Refugiada é a pessoa que foi forçada a deixar seu país de origem e requer "proteção internacional" devido a fundado temor de perseguição e risco de violência, caso volte para casa. Isso inclui pessoas que são forçadas a fugir de territórios em guerra. O termo tem suas raízes em instrumentos legais internacionais, notadamente a Convenção sobre o Estatuto dos Refugiados, de 1951, o Protocolo de 
1967 e a Convenção de 1969, da Organização da Unidade Africana (OUA). (ACNUR, 2019. p. 19).

Com o grande aumento do volume de migrantes forçados, sobretudo os refugiados, advindos das guerras civis, em países da África e do Oriente Médio aos países da Europa, problemáticas nacionais e externas são levantadas, o que alertaria para a possibilidade de que o século XXI viva sob a égide de uma crise migratória (GOMES; LOPES, 2017; FONTANA; ZIMNOCH; LORENTZ, 2017).

No Brasil, dados da Organização Internacional para as Migrações (OIM) mostram que a migração internacional no país cresceu $20 \%$ entre os anos de 2010 e 2015, estimando que, em 2018, vivessem, no país, 713 mil migrantes, dos quais 207 mil seriam provenientes de países da própria América do Sul (OIM, 2018). No entanto, de acordo com o Relatório Anual 2018: migrações e mercado de trabalho no Brasil (OLIVEIRA, 2018), elaborado pelo Observatório das Migrações Internacionais, OBMigra, o número de migrantes internacionais no país, de acordo com as estatísticas, presentes na base de dados do Sistema de Tráfego Internacional (STI) e do Sistema Nacional de Cadastro e Registro de Estrangeiros (SINCRE), sendo ambos pertencentes à Polícia Federal, foi de 1.221 .001 entre os anos 2000 e meados de 2018.

Com o elevado número de migrantes, questiona-se o papel desta população na sociedade contemporânea. Assim, também se faz necessário um rearranjo de políticas públicas que os alcance, suprimindo os medos internacionais e indo além das políticas de segurança pública, no intuito de que esses migrantes consigam ter assegurados seus direitos de construção de uma vida social digna no novo país. Logo, surge a demanda de que as sociedades globais, junto aos Estados, trabalhem pela integração social desses migrantes, garantindo-lhes a segurança e o acesso aos serviços básicos sociais (PRADO; COELHO, 2015).

No caso brasileiro, ainda segundo dados do Relatório Anual 2018: migrações e mercado de trabalho no Brasil (OLIVEIRA, 2018), do OBMigra, observou-se que é destacada a presença de adultos jovens e seu rejuvenescimento, ao longo dos anos: $48 \%$ dos migrantes se concentram no grupo etário de 25 a 40 anos de idade. A chamada população em idade ativa (PIA) é estimada em $90 \%$ dos migrantes, o que resulta numa importante oferta de trabalho (OLIVEIRA, 2018).

Em tese, essa população em idade ativa teria suas condições de trabalho asseguradas pelo decreto legislativo № 20, de 1965 (BRASIL, 1965) que, entrando em vigor, no ano de 1966, atentou-se às alíneas estabelecidas na Convenção sobre os Trabalhadores Migrantes da Organização Internacional do Trabalho (OIT). Tal convenção ocorreu em 1949, na cidade de Genebra, resultando no documento chamado Convenção sobre os trabalhadores Migrantes. Neste, membros da OIT se comprometeram a fornecer, aos migrantes, condições de trabalho, assegurando-lhes os direitos trabalhistas em suas políticas e legislações (OIT, 1949).

Mais recentemente, foi sancionada, no Brasil, a Lei da Imigração, Lei № 13.445, de 24 de maio de 2017. Nesta lei, ficaram instituídos os direitos e os deveres dos migrantes e visitantes em território nacional, sendo reguladas as políticas e diretrizes para esse público. Nela, está garantido o acesso igualitário dos migrantes às esferas laborais e de educação, a fim de que eles tenham pleno desenvolvimento econômico, político, cultural e social em solo brasileiro (BRASIL, 2017). 
Contudo, o que ocorre, na realidade, é uma precarização do trabalho migrante. Para Marinucci (2017), na tentativa de estarem inseridos no mercado de trabalho no país de trânsito ou destino, os migrantes encontram a redução dos direitos de trabalho junto à vulnerabilidade das circunstâncias, impostas pela condição de estrangeiro uma vez que, embora a precarização do trabalho seja presente, tanto aos nacionais quanto aos estrangeiros, registra-se, neste segundo grupo, maior vulnerabilidade (MARINUCCI, 2017).

Analisando a migração internacional no estado de São Paulo, Villen (2012) avalia que os migrantes, em sua maioria, ocupam postos de trabalho informais, precários e sem as devidas proteções legais. Os trabalhos a eles destinados limitamse às ocupações manuais e de baixa complexidade intelectual na indústria têxtil, nos setores domésticos, na construção civil e no comércio ambulante. De acordo com o mesmo autor, mesmo que os migrantes ou refugiados estejam no Brasil, de maneira legal, sua situação regularizada não é capaz de assegurar os direitos necessários. 0 resultado destes fatores é um processo de exploração econômica da força de trabalho migrante.

Tomando como base a Constituição Federal, Santin (2013) indica que, em tese, todos os trabalhadores migrantes possuem os mesmos direitos dos trabalhadores nativos brasileiros. Dentre esses direitos está o alcance a vagas de emprego, desde que possuam qualificações necessárias a tal cargo. Porém, quando se analisa a oferta de vagas, principalmente nos países desenvolvidos, depara-se com duas polaridades: os empregos, destinados à imigrantes com alto grau de formação acadêmica, ou os subempregos, destinados aos trabalhadores pouco qualificados.

Utilizando novamente os dados apontados pelo Relatório Anual 2018: migrações e mercado de trabalho no Brasil (OLIVEIRA, 2018), entre 2011 e 2017, foram concedidas 337.245 autorizações de trabalho para migrantes no Brasil das quais, a maior parte, foi destinada ao público masculino. Foram 301.116 autorizações masculinas e apenas 36.129 autorizações femininas. Em termos de escolaridade, essas autorizações foram destinadas, majoritariamente, aos migrantes com o ensino médio completo ou com o ensino superior completo.

Bógus e Fabiano (2015) citam que migrantes e refugiados, no Brasil, encontram diversos empecilhos que os impossibilitam a uma prática integral de sua nova cidadania. Destacando-se a discriminação dos governantes e da população sobre os fluxos migratórios, junto à ineficiência dos meios legais e o desconhecimento da população, que nega a garantia de seus direitos à burocratização documental, às dificuldades em relação ao idioma e ao difícil acesso destes migrantes a postos de trabalhos formais.

Sobre conhecimento da língua portuguesa, falando especificamente do público refugiado, está disposto no texto Refúgio no Brasil: caracterização dos perfis sociodemográficos dos refugiados, de Lima et. al. (2017), elaborado a partir de estudos do Instituto de Pesquisa Econômica Aplicada (IPEA), que apenas $21 \%$ dos refugiados, via elegibilidade, aqueles em primeira condição de refugiados, declararam dominar o idioma. A questão é ainda mais alarmante na esfera dos refugiados por reassentamento, ou seja, aqueles que precisaram encontrar um novo país de asilo, visto que, no primeiro país de acolhida, deixaram de existir as necessárias condições para sua segurança e integração, dentre eles, apenas $0,6 \%$ da população apresentou domínio sobre a língua portuguesa. 
Dessa forma, questiona-se como a educação brasileira está preparada para receber esse público migrante e refugiado. Será que na Rede Federal de Educação Profissional, Científica e Tecnológica do país existem oportunidades, cursos, políticas ou ações destinadas a esse público? Será que essa Rede tem atuado de forma a combater a marginalização do público migrante, por meio da sua capacitação, para a inserção em postos formais do mercado de trabalho?

No próximo tópico, serão apresentadas alguns elementos da política de internacionalização da Rede Federal de Educação Profissional, Científica e Tecnológica, assim como algumas de suas ações formativas, desenvolvidas para 0 atendimento aos migrantes.

\section{A INTERNACIONALIZAÇÃO NA REDE FEDERAL DE EDUCAÇÃO PROFISSIONAL, CIENTIIFICA E TECNOLÓGICA}

A Rede Federal de Educação Profissional, Científica e Tecnológica tem atuado com vistas a promover os processos de internacionalização em suas instituições. Utilizando os próprios documentos e diretrizes da Rede EPCT, proponhome, primeiramente, a traçar um panorama do conceito de internacionalização, na Rede Federal.

À luz da Política de Internacionalização da Rede Federal de Educação Tecnológica do Brasil (2017, p. 2),

[...] compreende-se a internacionalização como um processo que integra atividades que envolvem as diversas modalidades de mobilidade acadêmica, pesquisas colaborativas, projetos de desenvolvimento de ações, realizadas entre instituições de mais de um país, e desenvolvimento de aspectos curriculares que impactem na prática pedagógica no Brasil e/ou no exterior.

Esta mesma política suscita a importância do estabelecimento de uma proposta de relações internacionais concretas na Rede EPCT. Para tanto, apontamse alguns princípios norteadores como, por exemplo, a internacionalização como: (i) intercâmbio de conhecimentos e aprimoramentos da comunidade acadêmica, (ii) como estratégia de desenvolvimento, (iii) como promoção de solidariedade entre países e (iv) como meio para a difusão de atividades das instituições da própria Rede.

Já o Documento de Referência de Internacionalização, da Secretaria de Educação Profissional e Tecnológica, do Ministério da Educação (SETEC/MEC), define a internacionalização da Educação Profissional e Tecnológica como:

[...] o conjunto de ações, com vistas à prospecção e desenvolvimento de parcerias, alinhadas ao ensino, pesquisa, extensão e ao arranjo produtivo local, para oferta de educação de qualidade, formando uma comunidade acadêmica consciente, da cidadania global, capaz de compreender, articular e contribuir com os contextos local, regional e global. (p. 2) 
Nos seus objetivos, tal documento aponta para a necessidade de sensibilização da Rede EPCT sobre a importância das estratégias de internacionalização, o que se poderia obter a partir: (i) da ampliação das participações em eventos mundiais sobre a Educação Profissional, Científica e Tecnológica (EPCT); (ii) na divulgação do modelo brasileiro de EPCT, inclusive no intercâmbio de experiências na área; (iii) por intermédio do fortalecimento de EPCT nas regiões de fronteira; (iv) por meio da criação de uma base de dados sobre as ações de internacionalização da Rede; (v) por meio de uma política de línguas para a capacitação da comunidade acadêmica em idiomas estrangeiros; (vi) pelo intercâmbio de experiências; (vii) na cooperação Sul-Sul; e (viii) no desenvolvimento de metodologias e lideranças em EPCT. Cabe ressaltar que o referido Documento está alicerçado em três valores: a integração, o engajamento e a efetividade. Ademais, os objetivos supracitados têm ações estabelecidas em seis prioridades: "estruturação, integração das fronteiras, idiomas, ecossistemas de inovação, financiamento e cooperação" (p. 3).

Indo além, a Política de Internacionalização da Rede Federal de Educação Tecnológica do Brasil (2017) e o Documento de Referência de Internacionalização da SETEC/MEC apontam para a importância de que se estabeleçam estratégias de internacionalização na Rede EPCT. Nestes documentos, pode-se compreender que os princípios norteadores para esta educação, internacionalizada, estariam centrados no entendimento da internacionalização como uma das bases para o fortalecimento e o aprimoramento da educação, por meio do compartilhamento de conhecimentos e de experiências.

Contudo, embora estejam citadas as necessidades no compartilhamento dos saberes, na formulação de um currículo multicultural, na cooperação entre os países e na troca de experiências, não está presente, nesses documentos, a situação de discentes migrantes e refugiados em suas demandas e necessidades específicas ao acesso e a permanência na Rede EPCT. Além disso, poucas instituições apresentam propostas concretas a um ensino igualitário a estes estrangeiros. Como ações voltadas aos imigrantes e refugiados de Instituições da Rede Federal, pode-se citar as que seguem 7 :

- O Cefet-MG criou, em 2016, por meio de um projeto de extensão, o curso de Língua Portuguesa para estrangeiros, tendo como público principal os migrantes e refugiados haitianos, sírios e africanos;

- Aconteceu, em 2017, no CEFET-RJ, a palestra "O racismo antiimigrantes e refugiados e as políticas públicas no Brasil", realizado pelo Programa de Pós-graduação em Relações Étnico-Raciais (PPRER). $O$ evento recebeu Helion Póvoa Neto, da Universidade Federal do Rio de

\footnotetext{
${ }^{7}$ O levantamento das ações citadas neste artigo foi realizado a partir de pesquisa exploratória, nos portais eletrônicos das 41 instituições da Rede Federal de Educação Profissional e Tecnológica, no portal do Ministério da Educação (MEC) e no site do Conselho Nacional das Instituições da Rede Federal de Educação Profissional, Científica e Tecnológica (Conif), nos meses de abril e junho de 2020. Nos portais e no site do Conif, foram pesquisadas as seguintes palavras-chave: "imigrantes", "migrantes internacionais" e "refugiados".
} 
Janeiro (UFRJ) e do Núcleo Interdisciplinar de Estudos Migratórios (NIEM), e discutiu as temáticas migrantes em contextualizações históricas e atuais;

- Em 2018, as equipes de Ciências Sociais e de História, dos campi São Cristóvão II e III do Colégio Pedro II, promoveram o debate "Síria e a questão dos refugiados". Neste evento, foram discutidas questões como a guerra na Síria e a situação dos refugiados;

- Acontece no campus Santo Ângelo do Instituto Federal de Farroupilha (IFFAR) o projeto de extensão "Interação Linguística PortuguêsFrancês". Em 2019, o projeto promoveu encontros semanais, com duração de duas horas, para o aprendizado da língua portuguesa. Em contrapartida, uma das alunas do curso, Yvedrine Félix, ministrou uma oficina e um curso introdutório de francês para a comunidade acadêmica do campus.

- Também, em 2018, realizou-se, no Instituto Federal de Goiás (IFG), o vestibular para refugiados, previsto no edital no 053/2018. Este processo seletivo foi realizado, exclusivamente, a esse público, com o propósito de que os refugiados conseguissem ter acesso não apenas aos cursos da instituição, mas, principalmente, ao trabalho e à sociedade, por meio de uma formação adequada. Para participar desta seleção foi necessário que refugiados fossem reconhecidos no Brasil e portassem o diploma de nível médio;

- O Instituto Federal Goiano (IFGO) ofertou, em 2019, o curso em operação básica de computadores, na modalidade de cursos de formação continuada, para os migrantes haitianos, residentes no município de Aparecida de Goiânia. O IFGO buscou, em consonância com a Lei no 13.445, de 24 de maio de 2014 (Lei da Migração), por meio desse curso, promover uma acolhida humanitária e igualitária a esses migrantes;

- O Instituto Federal de Mato Grosso do Sul (IFMS) criou, em 2018, o projeto intitulado "Em questão: língua de acolhimento - Português para refugiados no contexto corumbaense". Esse projeto de pesquisa teve como propósito a realização do levantamento estatístico dos refugiados no município de Corumbá e a oferta de um curso de Língua Portuguesa aos mesmos. Destaca-se que o projeto em questão foi premiado na edição de 2018, da Feira de Ciência e Tecnologia do Pantanal (Fecipan), realizada em Corumbá;

- Por meio da Resolução 001/2018/CONSUP/IFPA, ficou instituída a ação afirmativa de garantia de vagas especiais aos refugiados, nos cursos de formação inicial e continuada ou qualificação profissional — FIC, Técnicos de Nível Médio e Superior de Graduação do Instituto Federal de Educação, Ciência e Tecnologia do Pará (IFPA). Para tanto, cada campus do IFPA deveria promover, anualmente, o processo seletivo especial, visando o ingresso de refugiados;

- O Instituto Federal do Paraná (IFPR) estabeleceu, em 2013, o projeto "Ensino de Português para Haitianos, no Município de Pinhais/Paraná". 
Esse projeto foi organizado em duas etapas: na primeira, voluntários, professores e outros profissionais receberam formação específica para 0 atendimento dos refugiados haitianos, na cidade de Pinhais. A segunda etapa do projeto foi dedicada à produção de materiais didáticos para o ensino da língua portuguesa a esses migrantes;

- Em 2018, aconteceu, no campus Duque de Caxias do Instituto Federal do Rio de Janeiro (IFRJ), o Encontro com Refugiados Africanos. O encontro foi promovido por professores de língua portuguesa. Neste, refugiados do Congo e da Angola, moradores dos arredores do Instituto, foram convidados para uma roda de conversa na qual se debateram as necessidades desse público refugiado;

- O Instituto Federal de Roraima (IFRR) tem se mostrado ativo sobre a criação e a oferta de projetos e ações para o público migrante e/ou refugiado. Esse instituto conta com o projeto de extensão "Língua Portuguesa para estrangeiros" no qual o ensino do idioma é oferecido aos refugiados e migrantes venezuelanos, haitianos, franceses e guianeses, residentes na região. Além disso, o IFRR conta, também, com o projeto "empreendedorismo social, voltado aos imigrantes venezuelanos", que trata sobre possíveis saídas socioeconômicas para os migrantes, residentes no estado de Roraima. Tal projeto foi apresentado no II Fórum Internacional da Amazônia (FIA), em 2019;

- O Instituto Federal do Rio Grande do Sul (IFRS) conta com um programa de extensão, voltado a migrantes haitianos e senegaleses. Neste, os migrantes podem enriquecer seus currículos com cursos de informática básica e costura, voltados diretamente a eles. Numa troca, e na valorização da integração dos saberes, os imigrantes oferecem aula de francês à comunidade acadêmica e externa do Instituto. Cabe ressaltar que este projeto foi premiado com o Prêmio Direitos Humanos, em 2018;

- O Instituto Federal de Santa Catarina (IFSC), a partir da demanda de empresários locais e no comprometimento com o Pacto Nacional Universitário pela Promoção do Respeito à Diversidade, da Cultura da Paz e dos Direitos Humanos, oferta, em diversos campi, os cursos de Idioma para Haitianos, de Língua Portuguesa e Cultura Brasileira, e o curso Empreendedoras Migrantes que visa orientar as mulheres migrantes em aspectos iniciais ou de profissionalização dos seus próprios negócios;

- Em 2017, o Instituto Federal de São Paulo (IFSP), fundamentado na Portaria no 1.838 , instituiu uma comissão de estudos com o intuito de que seja viabilizado o ingresso de refugiados e migrantes nos cursos da instituição;

- O Instituto Federal do Sudeste de Minas Gerais (IF SUDESTE MG), no Campus Santos Dumont, promoveu em 2019 o evento "Migração: pelos direitos das existências em movimento", por meio do projeto de extensão (R)Existências. Esse evento contou com participantes do Benin e da Venezuela. 
- Aconteceu, em 2018, no Instituto Federal do Sul de Minas Gerais (IF SUL MG), uma exposição fotográfica em homenagem ao Dia Mundial do Refugiado, batizada de "Entre olhares". O evento foi promovido pela Galeria Experimental do campus Sapucaia do Sul, em conjunto com a Associação Antônio Vieira, com a Agência da ONU para Refugiados (ACNUR) e com o Serviço Jesuíta a Migrantes e Refugiados (SJMR Brasil).

- Em 2015, o Instituto Federal Sul Rio Grandense ofertou o curso de português para imigrantes do Programa Nacional de Acesso ao Ensino Técnico e Emprego (Pronatec). O curso foi concebido na modalidade híbrida de ensino, intercalando aulas presenciais e períodos de estudo a distância, tendo duração de 160 horas. O público-alvo foram os migrantes e refugiados, residentes na região da grande Porto Alegre.

De maneira geral, é necessário observar que a visibilidade dos migrantes e refugiados é ainda pouco destacada na esfera da Rede Federal de Educação Profissional e Tecnológica. Conforme anteriormente citado, se na Lei da Migração, Lei № 13.445, de 24 de maio de 2017 (BRASIL, 2017), está garantida a plena inserção dos migrantes e dos refugiados no mundo do trabalho, logo faz-se necessário conferir, também, que eles necessitam de uma formação adequada, multicultural, livre de preconceitos e discriminação.

\section{CONSIDERAÇÕES FINAIS}

À medida que o fenômeno da globalização é intensificado, maximizam-se, também, os seus efeitos nas diversas instâncias sociais. O trabalho e a educação deixam de ser regidos apenas por forças locais e regionais e passam a responder a demandas supranacionais.

Para além desse cenário, propõe-se que os processos migratórios sejam uma das características presentes e que tendem a se intensificarem na sociedade contemporânea. Então, mais do que políticas de segurança, são necessários meios que fomentem a plena integração dos migrantes e refugiados nas esferas sociais.

Entretanto, o panorama que se apresenta é o de marginalização desses estrangeiros, diante da burocratização dos processos de integração, da falta de oferta de trabalho formal, da inserção dos mesmos em subempregos, das dificuldades burocráticas, da falta de domínio da língua portuguesa e, até mesmo, da xenofobia.

Nesse contexto, entende-se a educação como o meio para que a sociedade se desenvolva em parâmetros não apenas locais ou regionais, mas em dimensões globais. Então, questiona-se, também, o papel dessa educação no contexto da mobilidade humana, mais precisamente, nesse caso, no contexto dos processos migratórios no país e no mundo.

Junto ao desenvolvimento do indivíduo, cita-se, também, o desenvolvimento do meio socioeconômico onde ele está inserido, uma vez que, conforme apresentado nas pesquisas supracitadas, $90 \%$ dos imigrantes enquadram-se na chamada 
população em idade ativa. Portanto, seria um destacável aumento da mão de obra qualificada a ser ofertada no país.

Por intermédio de uma formação adequada, migrantes e refugiados poderiam alçar possibilidades de estarem inseridos de forma plena no mundo do trabalho. Nesse sentido, sugere-se que a Rede Federal de Educação Profissional, Científica e Tecnológica, apesar de ainda apresentar um conjunto relativamente baixo de ações formativas destinadas aos migrantes e refugiados, poderia ser vista como uma estratégia do Estado brasileiro para que esses estrangeiros conseguissem se desenvolver de forma educacional, laboral e, por consequência, social e econômica.

\section{REFERÊNCIAS}

ACNUR. Migrações, refúgio e apátrida. Guia para comunicadores. 1. ed. 2009. ACNUR. Cartilha para Refugiados no Brasil. 2018.

ALBUQUERQUE FILHO, Francisco Gutenberg. Política de Internacionalização da Rede Federal Educação Tecnológica do Brasil. Pelotas, 2017.

ANTUNES, Ricardo; ALVES, Giovanni. As mutações no mundo do trabalho na era da mundialização do capital. Educação \& Sociedade, v. 25, n. 87, p. 335-351, 2004.

BRASIL. Lei N 13.445 de 2017. Institui a Lei da Migração. 2017. Disponível em: http://www.planalto.gov.br/ccivil_03/_ato2015-2018/2017/lei//13445.htm. Acesso em 02 de setembro de 2019.

BRASIL. Decreto Legislativo No 20 de 1965. Aprova as Convenções de n's. 21, 22, 91, 93, 94, 97, 103, 104, 105, 106 e 107 e rejeita a de $n^{\circ}$ 90, adotadas pela Conferência-Geral da Organização Internacional do Trabalho. 1965.Disponível em: https://www2.camara.leg.br/legin/fed/decleg/1960-1969/decretolegislativo-20-30abril-1965-349517-publicacaooriginal-1-pl.html. Acesso em 02 de setembro de 2019.

BÓGUS, Lucia Maria M.; FABIANO, Maria Lucia. O Brasil como destino das migrações internacionais recentes: novas relações, possibilidades e desafios. Ponto e Vírgula - PUC SP - n. 18, 2015. p. 126-145.

CAMPOS, L.; CANAVEZES, S. Introdução à globalização. Lisboa: Instituto Bento Jesus Caraça, 2007.

CEFET RJ. Ciclo de palestras do PPRER: "O racismo anti-imigrantes e refugiados e as políticas públicas no Brasil". 2017. Disponível em: http://www.cefetrj.br/index.php/eventos-campus-maracana/3255-27-04-17-ciclo-de-palestras-dopprer-o-racismo-anti-imigrantes-e-refugiados-e-as-politicas-publicas-no-brasil. Acesso em 20 de maio de 2020.

COLÉGIO PEDRO II. SC promove debate sobre a questão dos refugiados da Síria. 2018. Disponível em: https://www.cp2.g12.br/ultimas_publicacoes/224not\%C3\%ADcias-2018/8880-sc-promove-debate-sobre-a-quest\%C3\%A3o-dosrefugiados-da-s\%C3\%ADria.html. Acesso em 20 de maio de 2020.

CONIF. Comissão estuda acesso de imigrantes e refugiados no IFSP. 2017. Disponível em: http://portal.conif.org.br/en/component/content/article/162-redefederal/1275-comissao-estuda-acesso-de-imigrantes-e-refugiados-no- 
ifsp? Itemid=620. Acesso em 07 de outubro de 2019.

Encontro com Milton Santos: 0 mundo global visto do lado de cá. Produção de Sílvio Tender. 2006.

FERRER. Walquiria Martinez Heinrich. A origem do processo de mundialização do capital financeiro. ARGUMENTUM - Revista de Direito - Universidade de Marilia, v. 1. 2001.

FONTANA, Eduarda; ZIMNOCH, Larissa; LORENTZ, Luísa Acauan. A crise migratória no século XXI: anomalia ou consequência da política internacional?. RIPE: Relações Internacionais para Educadores, v. 4. 2017.

FRANCO FILHO, Georgenor de Souza. Mobilidade humana e futuro do trabalho: efeitos da globalização. Revista DIREITO UFMS, Campo Grande, MS - Edição Especial - p. 187 - 198 - jan./jun. 2015.

GOMES, Geórgia; LOPES, Joana. A crise migratória no século XXI. RIPE: Relações Internacionais para Educadores, v. 5. 2017.

IFFAR. Projeto de extensão ministra curso de português para imigrantes haitianos em Santo Ângelo, 2019. Disponível em:

https://www.iffarroupilha.edu.br/ultimas-noticias/item/15933-projeto-deextens\%C3\%A3o-ministra-curso-de-portugu\%C3\%AAs-para-imigrantes-haitianosem-santo-\%C3\%A2ngelo. Acesso em: 08 de junho de 2020.

IFF. Plano de Desenvolvimento Institucional (PDI) do Instituto Federal Fluminense 2018-2022, 2017. Disponível em: http://portal1.iff.edu.br/acesso-ainformacao/gestao-e-planejamento/plano-de-desenvolvimento-institucional-pdi. Acesso em: 23 de maio de 2019.

IFG. IFG abre inscrições de vestibular para refugiados. 2018. Disponível em: http://www.ifg.edu.br/estudenoifg/17-ifg/ultimas-noticias/10368-vestibular-refugiados. Acesso em 20: de maio de 2020

IFGOIANO. Curso FIC em Operação Básica de Computadores. 2019. Disponível em: https://www.ifgoiano.edu.br/home/index.php/component/content/article/182ultimas-noticias-hidrolandia/11538-curso-fic-em-operacao-basica-decomputadores.html. Acesso em: 20 de maio de 2020.

IFMS. Projeto busca acolher refugiados por meio da Língua Portuguesa. 2018. Disponível em: https://www.ifms.edu.br/noticias/projeto-busca-acolher-refugiadospor-meio-da-lingua-portuguesa. Acesso em 20 de maio de 2020.

IFPA. Resolução No 001/2018/CONSUP/IFPA. Estabelece normas e os procedimentos que garantam aos refugiados o ingresso aos cursos de formação inicial e continuada ou qualificação profissional - FIC, Técnicos de Nível Médio e Superiores de Graduação. Pará. 2018. Disponível em: https://proen.ifpa.edu.br/documentos-1/13-resolucoes-do-consup/resolucao-doconsup/2018-2/1864-resolucao-n-001-2018-consup-ifpa-estabelece-normas-e-osprocedimentos-que-garantam-aos-refugiados-o-ingresso-aos-cursos-de-formacaoinicial-e-continuada-ou-qualificacao-profissional-fic-tecnicos-de-nivel-medio-esuperiores-de-graduacao. Acesso em: 21 de maio de 2020.

IFPR. IFPR desenvolve ações para inclusão e profissionalização de imigrantes haitianos no Paraná. 2013. Disponível em: https://reitoria.ifpr.edu.br/ifpr- 
desenvolve-acoes-para-inclusao-e-profissionalizacao-de-imigrantes-haitianos-noparana/. Acesso em: 20 de maio de 2020.

IFRR. Português para estrangeiros - Mais 172 imigrantes estão sendo capacitados. 2019. Disponível em: http://www.ifrr.edu.br/campi/boa-

vista/noticias/portugues-para-estrangeiros-2013-mais-172-imigrantes-estao-sendocapacitados. Acesso em 21 de maio de 2020.

IFRR. Projetos voltados a imigrantes venezuelanos são apresentados em evento internacional sobre a Amazônia. Disponível em:

http://www.ifrr.edu.br/campi/boa-vista/noticias/projetos-voltados-a-imigrantesvenezuelanos-sao-apresentados-em-evento-internacional-sobre-a-amazonia. Acesso em: 21 de maio de 2020.

IFRJ. Campus Duque de Caxias promove o $1^{\circ}$ encontro com refugiados africanos. 2018. Disponível em: https://portal.ifrj.edu.br/campus-duque-caxiaspromove-10-encontro-refugiados-africanos. Acesso em: 20 de maio de 2020.

IFRS. Projeto do IFRS com haitianos e africanos recebe Prêmio Direitos Humanos 2018. 2019. Disponível em: https://ifrs.edu.br/projeto-do-ifrs-comhaitianos-e-africanos-recebe-premio-direitos-humanos-2018/. Acesso em: 21 de maio de 2020.

IFSC. Câmpus oferecem oportunidades para aqueles que precisam recomeçar. 2019. Disponível em: https://www.ifsc.edu.br/conteudo-aberto/-

lasset_publisher/1UWKZAkiOauK/content/id/1630388/20-de-junho-c\%C3\%A2mpusoferecem-oportunidades-para-aqueles-que-precisam-

recome\%C3\%A7arhttps://www.ifsc.edu.br/conteudo-aberto/-

lasset_publisher/1UWKZAkiOauK/content/id/1630388/20-de-junho-c\%C3\%A2mpusoferecem-oportunidades-para-aqueles-que-precisam-recome \%C3\%A7ar. Acesso em: 06 de outubro de 2019.

IF SUDESTE MG. Projeto (R)Existências tem semana de atividades sobre migração e combate à xenofobia, 2019. Disponível em:

https://www.ifsudestemg.edu.br/noticias/santosdumont/2019/06/projeto-r-existenciastem-semana-de-atividades-sobre-migracao-e-combate-a-xenofobia. Acesso em: 08 de junho de 2020.

IF SUL MG. Galeria Experimental do câmpus Sapucaia do Sul promove Exposição fotográfica em homenagem ao Dia Mundial do Refugiado, 2018. Disponível em: http://www.ifsul.edu.br/ultimas-noticias/1934-galeria-experimental-docampus-sapucaia-do-sul-promove-exposicao-fotografica-em-homenagem-ao-diamundial-do-refugiado. Acesso em: 08 de junho de 2020.

IF SUL RIO GRANDENSE. Capacitação prepara docentes do curso do Pronatec de português para imigrantes. 2015. Disponível em:

http://www.ifsul.edu.br/ultimas-noticias/456-capacitacao-prepara-docentes-do-cursode-portugues-para-imigrantes-do-pronatec. Acesso em: 20 de maio de 2020.

IMDH. Guia de Informações sobre Trabalho para Imigrantes e Refugiados. 2017.

GRABOWSKI, Gabriel; KUENZER, Acácia Zeneida. A produção do conhecimento no campo da educação profissional no regime de acumulação flexível. HOLOS, [S.I.], v. 6, p. 22-32, out. 2016. ISSN 1807-1600. Disponível em:

http://www2.ifrn.edu.br/ojs/index.php/HOLOS/article/view/4983/1566. Acesso em: 08 
de junho de 2020.

LIMA, João Brígido Bezerra [et. al.]. Refúgio no Brasil: caracterização dos perfis sociodemográficos dos refugiados (1998-2014). Brasília: IPEA, 2017.

MEC. Documento de Referência de Internacionalização da SETEC/MEC.

Disponível em: http://www.ifpb.edu.br/relacoes-

internacionais/assuntos/Documentos/ri-internacinalizacao/documento-de-referenciade-internacionalizacao.pdf/view. Acesso em: 22 de maio de 2019.

MEC. Cefet oferece curso gratuito de português para estrangeiros. Disponível em: http://portal.mec.gov.br/component/tags/tag/36831. Acesso em 07 de outubro de 2019.

MARINUCCI, Roberto. Migrações e trabalho: precarização, discriminação e resistência. REMHU, Brasília, v. 25, p. 7-11, 2017.

MOURA, DANTE HENRIQUE; LIMA FILHO, DOMINGOS LEITE; SILVA, MÔNICA RIBEIRO. Politecnia e formação integrada: confrontos conceituais, projetos políticos e contradições históricas da educação brasileira. Rev. Bras. Educ., Rio de Janeiro, v. 20, n. 63, p. 1057-1080, Dec. 2015.

OIM. World migration report 2020. Genebra, 2019.

OIT. Convenção sobre os trabalhadores Migrantes, 1949. Disponível em: https://www2.camara.leg.br/atividade-legislativa/comissoes/comissoes permanentes/cdhm/comite-brasileiro-de-direitos-humanos-e-politica externa/ConvOITTrabMig.html. Acesso em: 02 de setembro de 2019.

OLIVEIRA, Antônio Tadeu Ribeiro de. Movimentação e registro de migrantes no Brasil: dados do STI e SINCRE. in: Relatório anual 2019, migrações e mercado de trabalho no Brasil. Ministério do Trabalho/ Conselho Nacional de Imigração e Coordenação Geral de Imigração. Brasília, DF: OBMigra, 2019.

ONU. Global compact for safe, orderly and regular migration. Marraquexe, 2018. ONU. International migration flows to and from selected countries: The 2015 revision. 2015.

PRADO, Erlan José Peixoto do; COELHO, Renata. Migrações e Trabalho. Ministério Público do Trabalho: Brasília, 2015.

SANDER, Brenno. Educação na América Latina: Identidade e globalização. Educação, v. 31, n. 2, maio-agosto, 2008, pp. 157-165.

SANTIN, Valter Foleto. Migração e discriminação de trabalhador. Argumenta Journal Law, Jacarezinho - PR, n. 7, p. 131-140, fev. 2013.

SANTOS, Isabel Cristina dos. Desfronteirização Organizacional: o domínio da relação tempo e espaço pelas organizações transnacionais. Revista Gerenciais, São Paulo, v. 2, p. 93 - 103, set. 2003.

SETEC. Visão de Futuro. 2019. Disponível em:

http://www.epsjv.fiocruz.br/sites/default/files/files/Documento\%20de\%20Vis\%C3\%A3 o\%20de\%20Futuro-\%20SETEC\%202019_vfinal\%20(1).pdf. Acesso em: 23 de maio de 2019.

THIESEN, Juares da Silva. Quem girou as chaves da Internacionalização dos currículos na educação básica? Educação em Revista, Belo Horizonte, v. 4. 2018. 
TORRES, Michelangelo Marques. Expansão capitalista e transnacionalização do capital: o poder global das corporações empresariais e a especificidade do caso brasileiro recente. Em Debat: Rev. Dig., Florianópolis, n. 7, p. 45-62, jan-jul, 2012.

TOSTA, Eline; KUNZ, Jaciel Gustavo. Mobilidade e Turismo: Construindo um Mapa Conceitual. Anais do V Encontro Semintur Júnior, Caxias do Sul, RS, Brasil, 2014.

UNESCO. Human migration and TVET. Discussion paper. Paris: UNESCO, 2019.

UNESCO. Greening Technical and Vocational Education and Training. A practical guide for institutions. Paris: UNESCO, 2017.

UNESCO. Educação para a cidadania global (ECG): a abordagem da UNESCO. Brasil. 2015. Disponível em:

http://www.unesco.org/new/fileadmin/MULTIMEDIA/FIELD/Brasilia/pdf/brz_ed_global _citizenchip_brochure_pt_2015.pdf. Acesso em: 21 de maio de 2020.

UNESCO. Recommendation concerning technical and vocational education and training (TVET). Paris: UNESCO, 2015.

UNESCO. Learning: Treasure Within. Paris: UNESCO, 1996.

UNEVOC. National Council for the Federal Network of Vocational, Scientific and Technological Education Institutions (Conif) UNEVOC Centre (National Body) since 2016. Disponível em

https://unevoc.unesco.org/home/Explore+the+UNEVOC+Network/centre=3063.

Acesso em: 21 de maio de 2020.

VILLEN, Patrícia. Polarização do mercado de trabalho e a nova imigração

internacional no Brasil. In: Seminário do Trabalho: Trabalho e Políticas Sociais no Século XXI, 8, 2012, Marília. Anais. Marília: Unesp, 2012. 